\title{
To Reduce Urban Disparities in Health, Strengthen and Enforce Equitably Environmental and Consumer Laws
}

\author{
Kenneth Olden, Rose Marie Ramos, and Nicholas \\ Freudenberg
}

\begin{abstract}
While observers agree that reducing disparities in health is an important health priority for the USA, there is little agreement and no comprehensive plan to achieve this goal. In this commentary, we make the case for reducing the disproportionate exposure to environmental and consumer hazards as a promising strategy for reducing health disparities. Exposures to environmental risks such as air pollution, lead, and hazardous wastes and to consumer products such as tobacco, alcohol, and unhealthy food have been identified as significant threats to health and important contributors to disparities in health. Strengthening the regulations that prevent exposure to these harmful substances and enforcing these rules equitably could bring benefits to the population as a whole and especially to the disenfranchised, primarily urban, populations that are most exposed. The current policy environment may present a window of opportunity for pursuing this strategy.
\end{abstract}

KEYWORDS Health disparities, Urban health, Health policy, Environmental health, Consumer protection

Growing evidence documents profound disparities in health between affluent and socioeconomically disadvantaged and white and black Americans. ${ }^{1-5}$ Compared with the majority of the American population, the poor and racial and ethnic minorities in the USA have reduced life expectancy and higher mortality and disease rates from diabetes, asthma, heart disease, stroke, hypertension, poor birth outcomes, and some cancers. ${ }^{6}$ In the USA, the life expectancy gap between the best off and the worst off is reported to be 15.4 years for males and 12.8 years for females. ${ }^{7}$ This disparity in mortality is due primarily to chronic diseases resulting from exposure to known environmental risks such as air pollution and occupational hazards and to health-damaging consumer products such as tobacco, alcohol, and high-calorie high-fat foods. ${ }^{8}$ Since $80 \%$ of the US population lives in metropolitan areas and cities concentrate poor people and income inequalities, these disparities in health are most heavily concentrated in urban areas.

Olden is with the School of Health Sciences, Hunter College of the City University of New York, New York, NY, USA; Olden is with the Department of Health and Human Services, National Institute of Environmental Health Sciences of the National Institutes of Health, Research Triangle Park, NC, USA; Ramos is with the Department of Health and Human Services, National Institute of Environmental Health Sciences, National Institutes of Health, Research Triangle Park, NC, USA; Freudenberg is with the Hunter College and Graduate Center, City University of New York, New York, NY, USA.

Correspondence: Nicholas Freudenberg, Hunter College and Graduate Center, City University of New York, New York, NY, USA. (E-mail: nfreuden@hunter.cuny.edu) 
Since the 1985 release of the Heckler Report, ${ }^{9}$ the first federal acknowledgement of racial/ethnic disparities in mortality, eliminating these inequities has been an important priority of many government and nonprofit agencies. ${ }^{10-12}$ Yet there has never been a comprehensive well-coordinated strategy for accomplishing this goal nor a national framework to coordinate research and policy or to translate detection of differences in disease burden into public health and medical practice.

It is therefore not surprising that, more than 20 years after the Heckler Report, disparities in life expectancy and rates of death and illness from many conditions persist and are in some cases widening. ${ }^{1}$ Economic trends such as increasing poverty and unemployment rates, dismantlement of safety net programs, the decline of wellpaying US manufacturing jobs that traditionally provided health care benefits, and the shift of health care costs from employers to workers suggest that these disparities will continue to grow.

The variability of disease incidence among US populations suggests that, by identifying the avoidable causes of these differences, it may be possible to develop strategies to mitigate their effects. Common explanations for disparities in health include differences in genetic predisposition, access to health care, socioeconomic and behavioral characteristics, cultural preferences, exposure to environmental hazards, or some combination of these. ${ }^{1-6,13,14}$

At the present, we can do little to modify the effects of genetics on human health, ${ }^{15}$ and modifying individual behaviors and cultural practices sufficiently to influence population health has proven to be difficult. ${ }^{16}$ Therefore, progress in eliminating disparities in health requires that we look upstream to social and environmental factors that are amenable to intervention through public policies.

Recently, policy makers have focused on reduced access to health care as an important modifiable contributor to the poor health of socioeconomically disadvantaged and minority Americans. ${ }^{17-19}$ Here, we make the case for reducing the disproportionate exposure to environmental and consumer hazards as another promising strategy for eliminating health disparities.

In the last three decades, US researchers have produced solid evidence on the health impact of exposure to environmental risks such as air pollution, lead, and hazardous wastes ${ }^{20-22}$ and to consumer products such as tobacco, alcohol, and unhealthy food. ${ }^{23-25}$ In many cases, the government has instituted regulatory and consumer protection policies that could reduce the burden of these exposures, offering added benefits to the disenfranchised, primarily urban, populations that are most exposed. The problem, in our view, is twofold. First, many environmental and consumer protection policies are not adequately or equitably enforced and, second, the regulatory approaches developed in the last century have not been updated to protect against current threats. Thus, our policy prescription for reducing disparities is to enforce existing policies more vigorously and equitably and to use scientific advances in the understanding of disease causation to modernize our approach to regulation.

\section{DISPROPORTIONATE EXPOSURES TO ENVIRONMENTAL HAZARDS AND UNSAFE PRODUCTS}

Humans are routinely exposed to a multitude of synthetic and natural agents and many of these exposures are known to cause cancer, birth defects, cardiovascular disease, diabetes, asthma, and neurologic disorders. ${ }^{8,26}$ To make our case, we will focus on five exposures, air pollution, salt, tobacco, lead, and hazardous wastes, that 
illustrate how these agents harm health and contribute to disparities and how more effective regulation could reduce these inequitable outcomes. Exposure to air pollution, specifically, to the particulate matter and sulfur dioxide generated from the combustion of fossil fuels, has been linked to adverse cardiovascular and pulmonary outcomes. ${ }^{27,28}$ For example, researchers estimated that living in a large US city translates to a $20 \%$ increased risk of a nonsmoker dying from lung cancer, roughly equivalent to the risk associated with a nonsmoker living with a smoker. ${ }^{29}$ More recently, Pope et al. showed that observed reductions in exposure to fine particulate air pollution were associated with about $15 \%$ of the increase in life expectancy in the 1980s and 1990s, with the greatest benefits accruing to the most polluted urban counties with high concentrations of poor and minority populations. ${ }^{20}$ An earlier survey found that $71 \%$ of Hispanics and $62 \%$ of blacks live in US areas where Environmental Protection Agency (EPA) air pollution standards had not been attained, compared with $52.5 \%$ of whites. ${ }^{30}$

In its report on salt, the American Medical Association estimated that $1.3 \mathrm{~g} /$ day lower lifetime salt intake would save 150,000 lives annually as individuals advance from age 25 to $55 .{ }^{31}$ Salt intake is an important risk factor for hypertension and cardiovascular disease, primary causes of death and disparities in the USA. In 1982, the Commissioner of the Food and Drug Administration called for reductions of salt in processed food but to date no regulations have been issued. In fact, in the last three decades, salt intake has actually increased in the USA by $55 \%$, primarily as a result of salt added to processed food. ${ }^{32}$

Tobacco remains the leading cause of death in the USA and, although blacks smoke less than whites, they experience worse outcomes from tobacco-related diseases. ${ }^{33,34}$ Through its product design, marketing, and retail distribution practices, the tobacco industry targets blacks and other racial/ethnic groups, practices that have not yet been addressed in the regulatory approaches to tobacco control. ${ }^{35,36}$ A study of enforcement of local smoking restrictions in Massachusetts concluded that differential regulatory practices may contribute to tobacco-related health disparities. ${ }^{37}$

African-American children are four times more likely to have elevated blood lead levels and seven times more likely to require medical intervention for lead poisoning than white children. ${ }^{38}$ Growing evidence also shows that the poor and racial and ethnic minorities live and work in environments where exposure to high levels of hazardous wastes is common. ${ }^{39-42}$ Although further research is needed to ascertain the burden of health disparities attributable to these factors, disproportionate exposures to hazardous wastes are well documented. A study found that communities with the largest percentage of minority residents had most of the toxic waste facilities, landfills, and superfund hazardous waste sites in the USA. ${ }^{43}$ For example, seven of the eight municipal incinerators and all five of the landfills in Houston, TX, USA are located in predominantly black or Hispanic communities. ${ }^{17,44}$ Studies of the association between cancer and the distribution of hazardous waste sites have shown that four common cancers (e.g., bladder, stomach, large intestine, and rectum) were statistically associated with the presence of toxic waste sites. ${ }^{44}$

In this area too, the enforcement of environmental regulation and cleanup is inequitable. On average, about 6 years elapse from the time that a toxic site is discovered until it is designated for cleanup. Studies have shown that it has taken twice as long for cleanup to be initiated in minority communities and that the remediation is less complete. ${ }^{45}$ Furthermore, penalties for violating EPA standards are six times higher in white communities than in minority communities. ${ }^{45}$ 


\section{CONCLUSION}

Research shows that neighborhood racial and ethnic and socioeconomic differences in exposures to environmental agents and unhealthy consumer products are major contributors to disparities in health. Therefore, adopting policies and practices that lower these exposures can significantly reduce disparities in health. Moreover, for the most part, the scientific and technological knowledge needed to implement more effective control strategies for exposures to agents such as air pollution, sodium, tobacco, or hazardous wastes are already known. Thus, policy makers can rely on "off-the-shelf" science to achieve these benefits.

Furthermore, environmental and consumer protection is a valued social objective. The USA has demonstrated its long-standing commitment to protecting health from the adverse effects of hazardous environmental agents and unsafe products through the establishment of multiple federal, state, and municipal regulatory agencies. With new political leadership and support from health professionals, our society should be willing to invest in this cost-effective strategy.

In fact, it was environmental interventions that led to the dramatic improvements in life span and quality of life in the twentieth century. By implementing public health practices that can translate these lessons for the twenty-first century, we can take an important step in meeting the challenge of eliminating socioeconomic and racial/ethnic disparities in health.

\section{REFERENCES}

1. Berkman LF. Social epidemiology: social determinants of health in the United States: are we losing ground? Annu Rev Public Health. 2009; 30: 27-41.

2. Banks J, Marmot M, Oldfield Z, Smith JP. Disease and disadvantage in the United States and in England. JAMA. 2006; 295: 2037-2045. doi:10.1001/jama.295.17.2037.

3. Woolf SH, Johnson RE, Fryer GE Jr, Rust G, Satcher D. The health impact of resolving racial disparities: an analysis of US mortality data. Am J Public Health. 2008; 98(Suppl (9)): S26-S28.

4. Ezzati M, Friedman AB, Kulkarni SC, Murray CJ. The reversal of fortunes: trends in county mortality and cross-county mortality disparities in the United States. PLoS Med. 2008; 5: e66. doi:10.1371/journal.pmed.0050066.

5. Olden K, White SL. Health-related disparities: influence of environmental factors. Med Clin North Am. 2005; 89(4): 721-738. doi:10.1016/j.mena.2005.02.001.

6. US Department of Health and Human Services. Health, United States, 2007, with Chartbook on Trends in the Health of Americans. Washington, DC: US DHHS; 2008.

7. Murray CJ, Kulkarni SC, Michaud C, et al. Eight Americas: investigating mortality disparities across races, counties, and race-counties in the United States. PLoS Med. 2006; 3(9): e260. doi:10.1371/journal.pmed.0030260.

8. Daar AS, Singer PA, Persad DL, et al. Grand challenges in chronic non-communicable diseases. Nature. 2007; 450(7169): 494-496. doi:10.1038/450494a.

9. Heckler MM. Report of the Secretary's Task Force on Black and Minority Health. Washington, DC: US Dept of Health and Human Services; 1985.

10. US Department of Health and Human Services. Healthy People: What are its goals? Available at: http://www.healthypeople.gov/About/goals.htm. Accessed on: October 2, 2008.

11. Council on Ethical and Judicial Affairs, American Medical Association. Black-white disparities in health care. JAMA. 1990; 263(17): 2344-2346. doi:10.1001/jama.263.17.2344.

12. National Quality Forum. Closing the Disparities Gap in Healthcare Quality with Performance Measurement and Public Reporting. Washington, DC: National Quality Forum; 2008. 
13. Murray CJ, Kulkarni S, Ezzati M, et al. Eight Americas: new perspectives on US health disparities. Am J Prev Med. 2005; 29(5): 4-10. doi:10.1016/j.amepre.2005.07.031. Supplement 1.

14. Freeman H. Race, poverty, and cancer. J Natl Cancer Inst. 1991; 83(8): 526-527. doi:10.1093/jnci/83.8.526.

15. Olden K. Human health and disease: interaction between the genome and the environment. In: Willard HG, Ginsburg GS, eds. Genomic and Personalized Medicine, vol. 1. Durham: Elsevier; 2008: 47-59.

16. Minkler M. Personal responsibility for health? A review of the arguments and the evidence at century's end. Health Educ Behav. 1999; 26(1): 121-140. doi:10.1177/ 109019819902600110.

17. Institute of Medicine, Committee on Environmental Justice, Health Sciences Policy Program. Toward Environmental Justice: Research, Education, and Health Policy Needs. Washington, DC: National Academy Press; 1999.

18. Institute of Medicine. Unequal Treatment: What Healthcare Providers Need to Know about Racial and Ethnic Disparities in Health Care. Washington, DC: National Academy of Sciences; 2002.

19. Institute of Medicine, Committee on Reviewing Evidence to Identify Highly Effective Clinical Services, Board on Health Care Services. Knowing What Works in Health Care: A Roadmap for the Nation. Washington, DC: National Academies Press; 2008.

20. Pope CA 3rd, Ezzati M, Dockery DW. Fine-particulate air pollution and life expectancy in the United States. N Engl J Med. 2009; 360(4): 376-386. doi:10.1056/NEJMsa0805646.

21. Levin R, Brown MJ, Kashtock ME, et al. Lead exposures in U.S. Children, 2008: implications for prevention. Environ Health Perspect. 2008; 116(10): 1285-1293.

22. Dearwent SM, Mumtaz MM, Godfrey G, Sinks T, Falk H. Health effects of hazardous waste. Ann N Y Acad Sci. 2006; 1076: 439-448. doi:10.1196/annals.1371.043.

23. Centers for Disease Control and Prevention (CDC). Annual smoking-attributable mortality, years of potential life lost, and economic costs-United States, 1995-1999. MMWR Morb Mortal Wkly Rep. 2002; 51(14): 300-303.

24. Centers for Disease Control and Prevention (CDC). Alcohol-attributable deaths and years of potential life lost-United States, 2001. MMWR Morb Mortal Wkly Rep. 2004; 53 (37): 866-870.

25. Wang Y, Beydoun MA, Liang L, Caballero B, Kumanyika SK. Will all Americans become overweight or obese? Estimating the progression and cost of the US obesity epidemic. Obesity (Silver Spring). 2008; 16(10): 2323-2330. doi:10.1038/oby.2008.351.

26. Ramos RG, Olden K. Gene-environment interactions in the development of complex disease phenotypes. Int J Environ Res Public Health. 2008; 5(1): 4-11. doi:10.3390/ ijerph5010004.

27. Dockery DW, Pope CA, Xu X, et al. An association between air pollution and mortality in six U.S. cities. N Engl J Med. 1993; 329: 1753-1759. doi:10.1056/NEJM199312093292401.

28. Raizenne M, Ness LN, Damokosh AI, et al. Health effects of acid aerosols on North American Pulmonary function. Environ Health Perspect. 1996; 104: 506-514. doi:10.2307/3432991.

29. Pope CA III, Burnett RT, Thun MJ, et al. Lung cancer, cardiopulmonary mortality, and long-term exposure to fine particulate air pollution. JAMA. 2002; 287(9): 1132-1141. doi:10.1001/jama.287.9.1132.

30. Brown P. Race, class, and environmental health: a review and systematization of the literature. Environ Res. 1995; 69(1): 15-30. doi:10.1006/enrs.1995.1021.

31. Dickinson BD, Havas S. Council on Science and Public Health, American Medical Association. Reducing the population burden of cardiovascular disease by reducing sodium intake: a report of the Council on Science and Public Health. Arch Intern Med. 2007; 167(14): 1460-1468. doi:10.1001/archinte.167.14.1460.

32. Briefel RR, Johnson CL. Secular trends in dietary intake in the United States. Annu Rev Nutr. 2004; 24: 401-431. doi:10.1146/annurev.nutr.23.011702.073349. 
33. Fagan P, Moolchan ET, Lawrence D, Fernander A, Ponder PK. Identifying health disparities across the tobacco continuum. Addiction. 2007; 102(Suppl 2): 5-29. doi:10.1111/j.1360-0443.2007.01952.x.

34. Northridge ME, Morabia A, Ganz ML, et al. Contribution of smoking to excess mortality in Harlem. Am J Epidemiol. 1998; 147(3): 250-258.

35. Primack BA, Bost JE, Land SR, Fine MJ. Volume of tobacco advertising in African American markets: systematic review and meta-analysis. Public Health Rep. 2007; 122 (5): 607-615.

36. Balbach ED, Gasior RJ, Barbeau EMRJ. Reynolds' targeting of African Americans: 19882000. Am J Public Health. 2003; 93(5): 822-827. doi:10.2105/AJPH.93.5.822.

37. Skeer M, George S, Hamilton WL, Cheng DM, Siegel M. Town-level characteristics and smoking policy adoption in Massachusetts: are local restaurant smoking regulations fostering disparities in health protection? Am J Public Health. 2004; 94(2): 286-292. doi:10.2105/AJPH.94.2.286.

38. Weintraub M. Racism and lead poisoning. Am J Public Health. 1997; 87(11): 1871-1872. doi:10.2105/AJPH.87.11.1871-a.

39. Olden K. The complex interaction of poverty, pollution, and health status. Scientist. 1998; $12(4): 7$.

40. Bullard RD. Dumping in Dixie: Race, Class and Environmental Quality. Boulder: Westview; 1990.

41. Soliman MR, Derosa CT, Mielke HW, Bota K. Hazardous wastes, hazardous materials and enviornmental health inequity. Toxicol Ind Health. 1993; 9(5): 901-912.

42. US General Accounting Office. Siting of Hazardous Waste Landfills and Their Correlation with Racial and Economic Status of Surrounding Communities. GAORCED-83-168. Washington, DC: US General Accounting Office; 1983.

43. United Church of Christ, Commission for Racial Justice. Toxic Wastes and Race in the United States: A National Report on the Racial and Socio-Economic Characteristics of Communities with Hazardous Waste Sites. New York: Public Data Access; 1987.

44. Griffith J, Duncan RC, Riggan WB, Pellom AC. Cancer mortality in U.S. counties with hazardous waste sites and ground water pollution. Arch Environ Health. 1989; 44 (2): 69-74.

45. Lavelle M, Coyle M. Unequal protection: the racial divide in environmental law. Natl Law J. 1992; 21: S1-12. 